\title{
SERO-EPIDEMIOLOGIA DE LA TOXOPLASMOSIS EN DOS COMUNIDADES DE RWANDA (AFRICA
} CENTRAL)

\section{RESUMEN}

Se ha estudiado la prevalencia de anticuerpos antitoxoplasma en dos comunidades rurales rwandesas, utilizando sangre total desecada en papel de filtro que se procesó por la técnica de Aglutinación Directa.

En ambas comunidades están afectados el $50 \%$ de los adultos. La adquisición de los anticuerpos se hace tardiamente en NGD (a los 14 años sólo un $12 \%$ de la problación muestra anticuerpos antitoxoplasma) y más pronto en NVU (31\% de la población estudiada tiene anticuerpos antitoxoplasma a los 14 años).

Se destaca el posible papel que juega esta enfermedad en la patología mater no fetal, y la necesidad de nuevos studios que aumenten el conocimien to de la epide miología de la toxoplasmosis y sus mecanismos de transmisión en Rwanda.

UNITERMOS: Toxoplasmosis, Rwanda, Sero-epidemiologia.

\section{INTRODUCCIÓN}

Debido a que en la mayoria de casos en que afecta a personas adultas la toxoplasmosis presenta una clínica banal y a que el diagnóstico serológico no es facilmente realizable en los paises tropicales, esta enfermedad es raramente diagnosticada en Rwanda, y poco estudiada su epidemiologia ${ }^{13}$. Sin embargo, la toxoplasmosis es una enfermedad que produce lesiones importantes en el feto, y también es potencialmente grave en enfermos inmunodeprimidos, lo que ha producido un resurgir de esta enfermedad como un problema mayor con el que se enfrentan los médicos en todo el mundo, sobretodo desde el inicio de la epidemia de $\operatorname{SIDA}^{5,11}$.
En este trabajo presentamos la prevalencia de anticuerpos antitoxoplasma en dos comunidades rurales rwandesas.

\section{MATERIAL Y METODOS}

El estudio se llevó a cabo en las municipios de Nyarutovu (NVU) y de Ngenda (NGD). Ambas son dos comunidades rurales; NVU situada en el norte de $R$ wanda, con un clima templado 8 $\left.-25^{\circ} \mathrm{C}\right)$ debido a la aititud (1800-2700 $\left.\mathrm{m}\right)$ y una pluviometria superior a los $1300 \mathrm{~mm}$ y NGD si tuada al sur del pais a una altitud media de 1400 $\mathrm{m}$, una pluviometria inferior a los $1000 \mathrm{~mm} \mathrm{y}$

(1) Hopital Nemba, Rwanda.

(2) Servei Microbiologia Clínica, Hospital del Mar, Barcelona, Espana

Direccion para la correspondencia: Dr. Josep M. Torres-Rodriguez. Servei Microbiologia Clinica - Hospital del Mar Passeig Maritim, 25.27-08003-Barcelona - Espanya. 
GASCON, J.: TORRES-RODRIGUEZ. J. M.: SOLDEvil. M. \& MERLOS. A. M. - Sero epidemiología de la toxoplas mosis en dos comunidades de Rwanda A Arica Central: Rev. Inst. Med. trop. S. Paulo, 31+6), 399.402, 1989

con las temperaturas más elevadas que NVU (temperatura media anual de $21^{\prime \prime} \mathrm{C}$ ).

NVU es un municipio densamente poblado (398 hab/ $\mathrm{km}^{2} ; 66.000$ habitantes) por paisanaje bien asentado y de la que algunas personas jóve nes tienen que emigrar debido a la falta de tierras de cultivo. NGD en cambio, es una zona que acoge personas provenientes de otros lugares de Rwanda y está menos poblada que la anterior « $100 \mathrm{hab} / \mathrm{km}^{2}: 75.000$ habitantes).

La higiene es precaria en ambas comunida des. Muchas familias tienen letrina pero la mayo ria de ellas no la usan. Lo mismo pasa con los estecoleros. Existen pocas familias que tengan gatos en sus casas, pero existen otros felinos (ga to salvaje, gato dorado, gato cervalı que habitan estas zonas.

La cabra y el carnero son los animales do mésticos más abundantes, seguidos del cerdo y la vaca. La cocción de los aiimentos, incluida la carne es tambien deficiente en $R$ wanda a cau sa de la escasez de madera. combustible usado en los hogares rurales.

De ambas comunidades se tomaron mues tras de sangre total de personas que no presen taban ninguna patología en el momento del studio, y que pertenecian a tres grupos de edad: pre escolares (1 - 6 años): escolares (7 - 14 años) y adultos (más de 15 años de edad). El grupo de NVU incluyó un total de 186 personas y el de NGD, 225. Su distribución por edades y sexo pue de verse en la tabla 1.

TABLA 1

Grupos estudiados y resultados del estudio por lugar de residencia, edad y sexo.

\begin{tabular}{|c|c|c|c|c|c|c|c|c|}
\hline & Varon & $\mathrm{N}+$ & $\%$ & Hembra & $\mathbf{N}+$ & $\%$ & Total & $\%$ \\
\hline \multicolumn{9}{|l|}{ NVU } \\
\hline Adultos & 37 & 20 & 54 & 27 & 12 & 44.4 & 64 & 50 \\
\hline Escolares & 33 & 11 & 33.3 & 28 & 8 & 28.57 & 61 & 31 \\
\hline Pré escol. & 31 & 1 & 3.2 & 30 & 1 & 3.33 & 61 & 3.2 \\
\hline \multicolumn{9}{|l|}{ NGD } \\
\hline Aduitos & 40 & 26 & 65 & 35 & 12 & 34.3 & 75 & 50 \\
\hline Escolares & 37 & 5 & 13.5 & 38 & 4 & 10.5 & 75 & 12 \\
\hline Pré escol. & 36 & 0 & 0 & 39 & 2 & 5.12 & 75 & 2.6 \\
\hline
\end{tabular}

n $+=$ número de casos positivos

Las muestras se obtuvieron por puncion di gital, fueron depositadas en papel Whatman $\mathrm{n} 2$ y enviadas al Hospital del Mar (Barcelona para su procesamiento. Para la deteccion de an ticuerpos antitoxoplasma se utilizó la prueba de Aglutinación Directa (kits toxo-screen DA: Bio mérieux, Lyon según metodología descrita en otros trabajos ${ }^{3.6 .7}$ a la dilución de $1 / 40$, conside rada discriminativa.

23 de. las muestras fueron procesadas dos veces para testar la reproductibilidad del mé todo.

Los resultados hallados se contrastaron con el método estadistico del $\mathrm{X}^{2}$.

\section{RESULTADOS}

Las 23 muestras que se procesaron por se gunda vez dieron todas el mismo resultado que en la primera ocasión.

En ambos ayuntamientos, el $50 \%$ de los adultos dieron resultado positivo en la detección de anticuerpos antitoxoplasma. Los resultados en los niños de edad pre-escolar, similares en ambos ayuntamientos, oscilaban entre el $2.6 \%$ (NGD) y el $3.2 \%$ (NVU). Las mayores diferencias se pro dujeron en el grupo de edad escolar: 19 de ellos dieron positivo en NVU ( $31 \%)$ y 9 en NGD $12 \%)$. 
GASCON, J.: TORRES RODRIGUEZ, J. M.: SOLDEVILA. M. \& MERLOS. A. M. - Sero epidemiologia de la toxoplas mosis en dos comunidades de Rwanda Africa Centrali. Rev. Inst. Med. trop. S. Paulo, 31(6).399402.1989.

En los adultos, los hombres obtuvieron mayor porcentaje de positividad que las muje res, no significativo en NVU pero si en NGD (p $<0.01$ ).

Los resultados pueden verse en la tabla 1.

\section{DISCUSIÓN}

Para la discusión del método utilizado tanto para la obtención de las muestras como para su procesado nos remitimos a trabajos anterio $\operatorname{res}^{3.6 .7}$

El estudio revela un alto porcentaje $(50 \%)$ de seropositivos en la población adulta de Rwan da. La única diferencia estadisticamente signifi cativa $\left(\mathrm{X}^{2}=7.03 \mathrm{p}<0.01\right.$ ) es entre sexos en el ayuntamiento de Ngenda. En otros trabajos también se han encontrado diferencias entre se$\operatorname{xos}^{9} \sin$ que exista una explicación clara a este hecho.

Entre la población escolar si hay diferencias de una comunidad a otra. Una explicación de este hecho podria ser que al ser la región de NGD, menos húmeda que la de NVU, haya una menor prevalencia de la enfermedad, al sobrevivir peor los ooquistes del parásito en ambiente seco ${ }^{10 .}{ }^{12}$. Los adultos del ayuntamiento de NGD tendrían el patrón epidemiológico de su lugar de origen.

Los resultados obtenidos son similares a los encontrados en estudios epidemiológicos reali zados en otros paises africanos en lo que se refie re a personas adultas ${ }^{2.8 .15}$. Sin embargo un estu dio realizado con niños en Kenya ${ }^{1}$ muestra unas prevalencias mucho más altas que las obtenidas por nosotros en Rwanda.

El aumento de positividades crece con la edad $138 \%$ de seropositivos lo son a partir de los 15 años en NDA, y el $19 \%$ en NVU) estando la población femenina en edad de procrear más expuesta a la infección por Toxoplasma gondii que en otras comunidades donde ésta se realiza a más temprana edad.

En el Hospital de Nemba (municipio de NVU) se atendieron en 1985, 97 abortos, hubo 73 nacidos muertos de un total de 726 nacimientos (similar a otros centros rwandeses ${ }^{4}$ ) de los cuales, algunos casos padecian alguna malfor mación congenita visible (hidrocefalia y otras. Las causas de toda esta patologia se desconocen pero bien podria la toxoplasmosis contribuir a ella, al igual que en los casos de infertilidad, tal como sugieren los datos de otros estudios ${ }^{3 .}$.

$R$ wanda es un pais con prevalencia de anti cuerpos anti-HIV elevada, en el que se han des crito bastantes casos de SIDA (987 hasta Marzo $1988)^{14}$. La toxoplasmosis adquirirá sin duda im portancia como complicación de este sindrome.

El mecanismo de transmisión de la toxoplas mosis en Rwanda no está esclarecido. Es muy probable que la transmisión humana se haga al ingerir carne insuficientemente cocida de ani males (vaca, cerdo, carnero, cabra) que pastan libremente en cualquier terreno. Los felinos sal vajes actuarian como diseminadores de ooquis tes

Creemos que seria importante un studio más profundo de la epidemiologia de la toxoplasmo sis, a fin de establecer con precisión los meca. nismos de su transmisión y su responsabilidad en la numerosa patología materno-fetal que afli ge a la población rwandesa. También seria im portante el estudio de la prevalencia de la infec ción en los animales domésticos.

\section{SUMMAR Y}

\section{Sero-epidemiology of toxoplasmosis in two areas of Rwanda (Central Africa)}

We collected dry blood specimens from two rural areas in $\mathrm{R}$ wanda, that were tested for anti bodies to Toxoplasma gondii through the Direct Agglutination technique.

$50 \%$ of the adults in both communities had antibodies to T. gondii. The Ngenda (NGD) po pulation apparently acquired antibodies at a la ter stage of its life conly $12 \%$ were positive at 14 years of age). The Nyarutovu (NVU) popula tion already showed a $31 \%$ positivity at the same age.

We would like to point out the pathogenic role played by toxoplasmosis during pregnancy and the need of new studies about the epidemio 
GASCON, J.; TORRES RODRIGUEZ. J. M.: SOLDFVILA. M. \& MERLOS. A. M. - Sero epidemiologia de la toxoplas mosis en dos comunidades de Rwanda (Africa Central). Rev. Inst. Med. trop. S. Paulo, 31(6), 399402,1989

logy of the disease as well as the transmission mechanism in $\mathrm{R}$ wanda.

\section{REFEREN CIAS}

1. HOWRY, T. R: CAMARGO, M. E. \& KINYANJUI, M - Sero cpidemiology of Toxoplasma gondii infextion in young children in Nairobi. Kenya. Trans. roy. Soc. trop. Med. Hyg., 80: $439441,1986$.

2. CARTER.F. S. \& FLECK. D. G. - The ineide ne of Tox, plasma antibodies in the Sudanese. Trans roy. Soce trop. Ned. Hy

3. COUZINEAC. P. \& BAUFINE DUCROQ. H. ... ARght nation directe des toxoplasmes. Preparation de lantigene ot cxamen de 400 serums. Ann. Biol. clin., 28: 411415 1970.

4. DE CLERCQ. A. -.. Problemes en obstetrique et grifeco logie. In: Sante et maladies au Rwanda. Bruxelles Adm nistration Generale de la Cooperation au Developpement. 1982. p. 627656

5. DE CLERQ. D : HENRY. M. C. \& LOKOMBE. B SPOl gical observations on toxoplasmosis in Zairian AIDS pa tients Trans roy Soc trop Med Hyy 80:613614, 1986

6. DESMONTS, G. \& REMINGTON, J. S. Direct agglut nation test for diagnosis of Toxoplasma infection method for increasing sensitivity and specificity. J. clin. Micro biol., 11: 562568,1980 .

7 GASCON J. TORRES RODRIGUEZ J M \& GONZA LEZ, C. -. Utilidad de las muestras de sangre total dese cada en papel ae filtro en la deteceien dr anticuerpos anti toxoplasma Rev. Inst. Med, trop. S. Paulo, 31: 100102 1989

8. GRIFFIN, L \& WILLIAMS, K. A. B. -.. Sernogical and parasitological survey of blood donors in Kenya for toxo plasnosis. Trans. roy. Soc. trop. Med. Hyg. $77: 763766$. 1983

9. KHADTE, M. A. \& EL NAGEH, M. M . Serological Sur vey for toxoplasmosis in Tripoli. S.P.L.A.J. (Libya) Trans roy. Soc. trop. Med. Hyg.. 81: 761763.1987

10. LUDLAM. G. B.-. Toxoplasma antibodies in inhabitants of the Niger Delta Trans. roy. Soc. Irop. Med. Hyg., 59: 8386,1965

11. LUFT, B. J.: CONLEY, F. \& REMINGTON. J. S. -. OUt break of central nervous system Toxoplasmosis in Wes tern Europe and North America. Lancet, 1: 781783.1983.

12. NOZAIS. J O.: DOUCET. J.: TIACOH, L \& GUEUNIER. M. - Etude de la prevalence de la toxoplasmose en cote d'Ivoire (Rósultats portant sur 4.769 serum etudies par immunofluoresecences. Med. trop. (Mars)., 35:413 417.1975.

13. WANDERICK F R - Toxoplasmose In Sante et maídies au Rwanda. Bruxelles. Administration Grnerale de la Cooperation au Developpement, 1982. p. 464467.

14. WHO Aecuired immunodefieteney syndrome (AIDS) data as at 31 August 1988. Wkly. epidem. Kee., 63: 277278 1988

15. ZARDI. O.: ADORISIO. E.: HARAFE. O. \& NUTI. M - Serological survey of toxoplasmosis in Somalia. Trans. roy. Soc. trop. Med. IIyg., 74: $577581,1980$.

Reccbido para publicaça em 2021989. 